\title{
Implementing Six Sigma in Challenging Times: A Case Study
}

\author{
Jose Hernandez and Trevor Turner, \\ DMEM, University of Strathclyde, James Weir Building, \\ 75 Montrose St, Glasgow, UK, G1 1XJ \\ jose.hernandez@strath.ac.uk, t.turner@strath.ac.uk
}

\begin{abstract}
This paper presents the findings of a two year Knowledge Transfer Partnership (KTP) project between the University of Strathclyde and a small Scottish manufacturing company. The aim of this KTP is to bring stability and continuity to the organisational processes of the business by introducing Six Sigma. The paper discusses the effects that the current economic climate has had in the business and presents the findings of a Six Sigma project implementation.
\end{abstract}

Keywords: Six Sigma, SMES, Cost of Quality (COQ), Recession.

\section{Introduction}

This paper presents the findings of a two year Knowledge Transfer Partnership (KTP) project between the University of Strathclyde and a small Scottish manufacturing company. KTP is a UK wide programme aimed at helping businesses become more competitive through the use of the knowledge and skills that exist within academic institutions.

This KTP project will be concluded in November of 2009 and its aim is to bring stability and continuity to the manufacturing processes of the partner company by introducing the Six Sigma approach.

Six Sigma is a recognised Quality Improvement tool aimed at reducing and controlling variation in strategically selected processes to achieve the required customer specifications.[1] The potential benefits that Six Sigma can create in terms of cost savings and improved customer satisfaction have been widely documented and proved by many organisations around the globe.[2,3] Despite the successes from many high profile organisations the adoption of this practice by UK enterprises particularly SMEs is not widespread.

Six Sigma practitioners suggest that the introduction of Six Sigma is more challenging in SMEs in comparison to large manufacturing firms.[4] The rationale is that in SMEs employees tend to fulfil an array of functions and are therefore more likely to be distracted by external \& internal business pressures. In addition, the organisational structure of some SMEs discourages the introduction of dedicated Six Sigma Black Belts to complete projects as this approach is deemed impractical and financially difficult to justify. 
As a result of the above the involvement from Senior Management to actively support and drive the introduction of Six Sigma becomes increasingly critical. This resource requirement in combination with the current economic climate has the potential of further reducing the adoption of Six Sigma by industry. Companies in their struggle to remain profitable during recession periods have taken drastic measures to reduce their internal expenditure. Regrettably in some cases this involves the disruption of fundamental quality practices as they are considered non value adding activities.[6]

Few companies have truly achieved Six Sigma levels of quality. However, in the authors' experience small process improvements have the potential to create significant benefits for a business. The introduction of Six Sigma can be a daunting experience and it will require understanding of the practice, resources and a disciplined approach from the organisation. However, the cost of not addressing quality issues properly i.e. identification and elimination of the root cause, and failing to meet the customer requirements will be far more costly in the long term.

It is important to mention that due to the sensitivity and nature of the information disclosed in this paper the company wishes to remain anonymous and will be referred to in this paper as Company B.

\section{Background to the Company}

Company B is a well established business that manufactures bespoke timber wood windows and doors. Over the years the company has invested in developing its brand and today the company is recognised as a provider of bespoke high quality timber wood products. In the past 5 years the business has developed good links with academic institutions and has participated in 2 previous KTP programs which increased the business manufacturing capacity by $25 \%$. Even though the turnover increased considerably the profit margins were smaller than expected. The reason behind this was an increase in the business' operational costs as a result of an increase in both internal and external failures.

It is understood that the business used to capture data on defects during final inspection. However, the information gathered was not being used to remove failure modes leading to customer complaints. As a result customer complaints have increased significantly since 2007 . This shows lack of understanding of the COQ model i.e. failure, appraisal and prevention. The inspection activity (appraisal) was not being used strategically to introduce process improvement actions (prevention) to reduce customer complaints and quality costs (failures).

The Company recognised that it required external support and knowledge to improve the reliability of its products and decided to embark on a third KTP project aimed at reducing the Cost of Quality (COQ). Evidence suggests that COQ can account for up to $40 \%$ of the annual Operating Cost of an organisation.[7] In the case of Company B this represents a cost of $£ 3.2 \mathrm{M}$ per annum.

It was understood from the outset that change management issues would be a risk to the project. Approximately one third of employees have worked for the company for over 20 years. During that period a number of Continuous Improvement and Quality initiatives were attempted but due to external business pressures, lack of ownership and the lack of a structured implementation approach the initiatives were abandoned. 
It is well known that companies that fail in their first attempt at introducing change find it increasingly difficult to reintroduce similar practices as behavioural issues and change resistance attitudes become deeply rooted.

However, it was considered advantageous that the company had previously worked on KTP projects and was therefore familiar with the conditions needed for its success.

\section{Methodology}

The methodology used throughout this project is Action Research. Action Research promotes action through change and follows an iterative cycle of action and reflection. [8] The change in this case is the introduction of a strategic approach to Continuous Improvement.

The researcher working on this KTP was embedded in the partner company for the duration of the project. However, he is officially a member of the academic institution. This longitudinal research approach enabled the researcher to gather consistent data from the business whilst allowing him to act exclusively in the introduction of Six Sigma into the business. Research suggests that one of the Critical Success Factors behind Six Sigma implementation is having a dedicated Black Belt to complete projects.[9]

The researcher undertaking this KTP fulfilled the function of Black Belt and was responsible for the facilitation of Six Sigma projects and training of teams in the use of reliability tools and techniques.

\subsection{The Current State}

The first phase of this project involved familiarising the researcher with the organisation. This enabled the researcher to discover the current state of the business. An initial examination showed that Company B interacts with its customers mainly through the sales department which is responsible for capturing product stipulations such as quantity, type, finish, etc. This allows the company to manufacture products to specification but it fails to capture the unspoken needs of the customer.

Understanding the customer requirements is one of the critical success factors for Six Sigma and therefore was a logical starting point for this project. The Company does not actively seek feedback from its customers. However, the company does capture information from clients in the form of customer complaints.

The initial examination of the organisation also highlighted fundamental flaws in the processes followed to select and undertake Continuous Improvement Projects. Not only was the selection of projects ad hoc but financial considerations such as expected benefits, resource allocation, scoping and duration were not clearly defined. As a result, on occasions projects ran for longer than expected. Some of these projects were abandoned as other projects deemed as "more important" took priority and those which were completed failed to demonstrate benefits to the business.

\subsection{A Strategic Approach to Continuous Improvement}

The second phase of this project involved introducing a strategic approach to project selection and problem solving. The customer complaints were analysed by means of a 
Pareto diagram to illustrate how this information could be used strategically to identify areas of improvement.

Based on the findings from this analysis a number of Six Sigma Continuous Improvement projects were undertaken. The aim of these projects was to:

- Create a critical mass of individuals that would be familiar with Continuous Improvement tools and techniques and that would eventually be trained to Six Sigma Green Belt level.

- Demonstrate the importance of a strategic approach to Continuous Improvement.

- Modify attitudes and perceptions of those involved towards change.

\section{The Effects of a Global Recession}

In November of 2008 Company B began to witness a slowdown in its product demand as a result of the financial crisis affecting the construction \& manufacturing sectors. The current situation was quite severe during the first trimester of 2009 as its product demand was reduced by $90 \%$ in comparison to previous years. This caused cashflow problems which forced the company to cut its expenditure and release a considerable number of employees. This had an impact in all on going KTP Continuous Improvement projects as resources were pulled out to fulfil other functions in the business that were perceived as more critical. During the cutback process all quality administrative salaries were terminated. As a result, all Company led Continuous Improvement initiatives and practices including quality inspection and internal audits were abandoned.

This action was necessary to allow the company to survive and continue in operation.

Despite the above the Company decided to continue with the KTP as the project had already generated benefits and was well underway. However, it was agreed that the researcher would have limited access to the resources of the Company. Unfortunately this meant that:

- All on going Continuous Improvement projects undertaken through the KTP project would be temporarily stopped.

- The already programmed but not commenced Continuous Improvement projects would have to be redefined and scoped as the researcher would have to take a more hands on approach and perform a majority of the project activities.

- The data capture would be constrained to smaller samples reducing the statistical significance of results.

- Brainstorming sessions and collaborative work would be replaced by informal conversations and shadowing.

- $\quad$ No more training programmes would be introduced into the business.

\section{The Post-Recession Six Sigma Project}

This section will present a recently commenced Six Sigma project aimed at improving the reliability of glazing beads and which commenced in April 2009. 
The analysis of customer complaints previously discussed showed that paint delaminating is the most common failure in the company's products. The researcher shadowed the field service team during a number of customer visits aimed at dealing with delaminating failures. A close examination of failed windows highlighted that there is a relationship between poorly fitted beads and paint delaminating issues. Furthermore, it was suggested by the field service operators that poorly fitted beads have the potential to critically affect the reliability of products by causing water ingress failure.

A more in depth study of the bead manufacturing process highlighted a number of quality issues, e.g. broken beads, excess clearance and poor mitre joints. These issues are frequently identified during the final assembly process and rectified during a touch up operation after the product has been fully assembled. It is important to mention that this is a non value adding activity and as demonstrated by our customer complaints not always successful.

This highlighted the importance of identifying the true root causes behind the lack of consistency in beads and introducing a robust solution.

\subsection{Data Capture}

A standard definition for flawed beads was created and used to capture data on bead related failures prior to the touch up operation.

Bead quality issues were classified into 5 main failure modes. This study highlighted that $29 \%$ of our beads get damaged during the manufacturing and assembly process; $22 \%$ have poor material finish; $20 \%$ are loose or show excess clearance; $13 \%$ have poor joints; and $11 \%$ project from the sash.

Each of these failure modes had subcategories to allow for a more detailed analysis. This enabled the researcher to link the individual failures to the responsible manufacturing processes. The following Pareto diagram in Figure 1 shows the findings from this exercise.

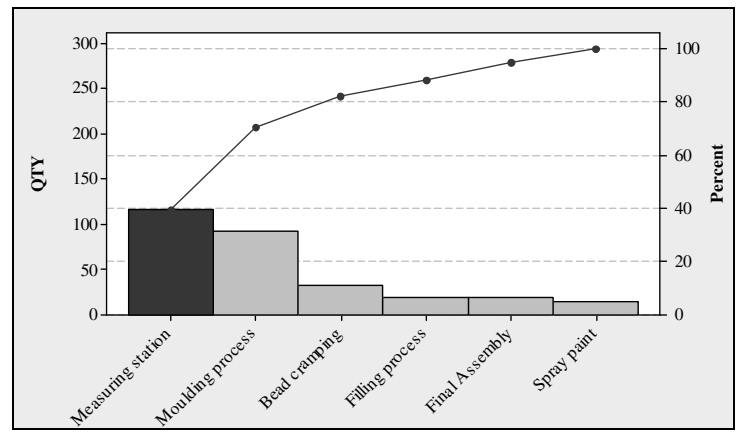

Fig. 1. Pareto of Bead Failures by Process

\subsection{The Cost of Quality}

Concurrently to the data capture stages the COQ for this particular failure was established. This exercise was undertaken to justify further investigation and create a cost 
estimate for process improvements. Members from the production and engineering team were involved in this process to achieve an accurate estimate. It was discovered that the COQ for bead failures was of approximately $£ 68,000$ per annum and is broken down as follows in Figure 2.

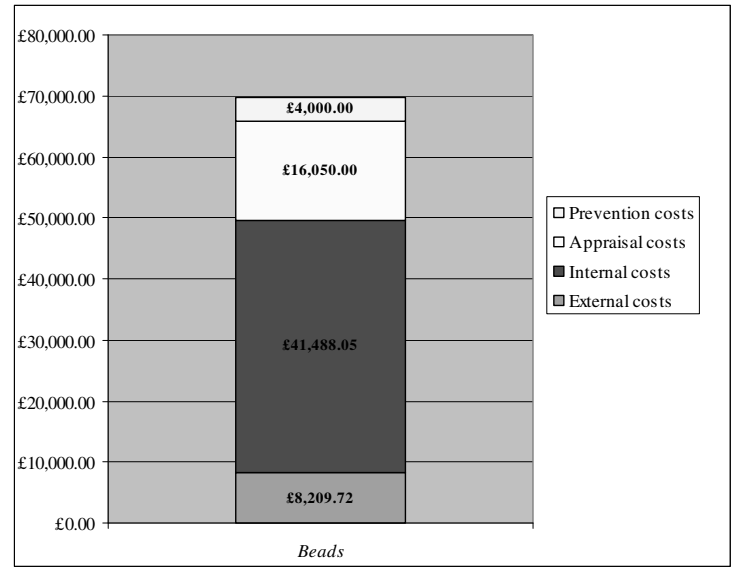

Fig. 2. Cost of Quality Model

External and internal failures represent roughly $70 \%$ of the COQ for beads and appraisal and prevention costs represent approximately $23 \%$ and $6 \%$ respectively. This is a shocking discovery if we consider that in organizations in which COQ is $40 \%$ of their running costs the breakdown is $50 \%$ for failures, $38 \%$ appraisal and $13 \%$ prevention. The current situation of the business is not healthy and it highlights the stress that the current economic situation is putting on the business.

\subsection{Analysis and Solution}

Due to the resource limitations previously discussed the decision was made to focus only on the most critical process affecting the reliability of beads i.e. the measuring station.

A Type 1 Gauge study was used to asses the accuracy of the measuring machine. The findings from the study highlighted that the machine was incapable of achieving repeatable measurements as significant bias from human interaction is present. As a result, beads are frequently sized incorrectly which causes dimensional fitting issues during the final assembly process such as breakages and excess clearance in beads. It was understood that the business would be against acquiring new equipment and as a result the decision was made to modify and refurbish the measuring station.

The machine was refurbished and modified during the summer shutdown to prevent interference with production. A similar repeatability analysis (See figure 3) was undertaken to observe improvements in the measuring station. 


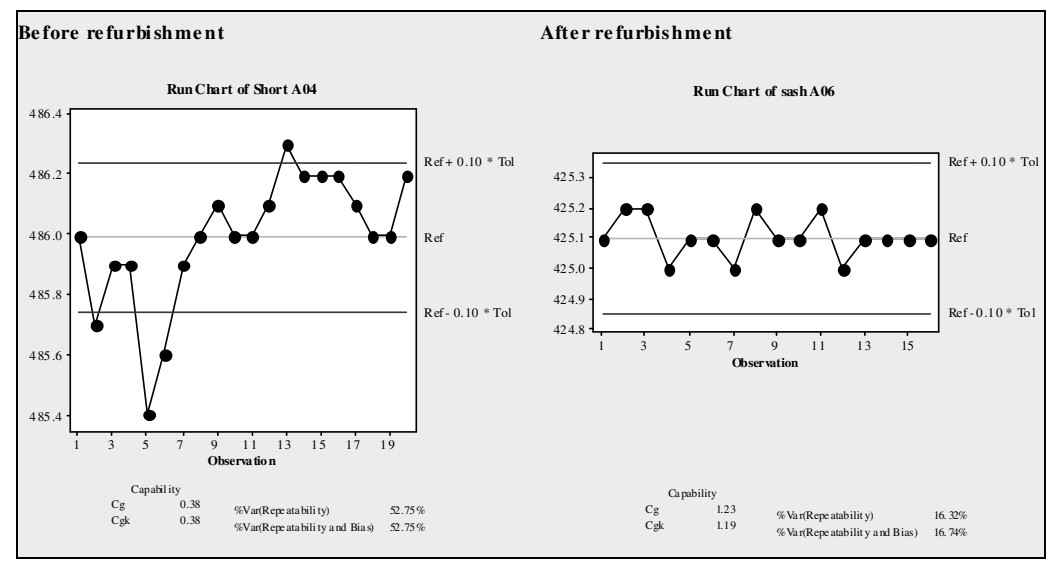

Fig. 3. Findings from repeatability study for the bead measuring station

The repeatability of the machine was improved significantly although there is still a degree of bias caused by the human interaction. Unfortunately this bias can only be eliminated if an automated system replaces the existing manual system. Regardless, the improvements made have the potential to eliminate $40 \%$ of bead related failures and consequently generate annual savings to the business of $£ 27,200$. This is without considering intangible benefits such as improved customer satisfaction and reduced manufacturing cycle times.

\section{Discussion}

The Action Research has revealed that Company B was unable to sustain Continuous Improvement activity during the current recession and cost cutting needed for survival of the business has led to an increase in customer complaints. This in turn has led to an increase in operating costs associated with COQ as a consequence of the reduction in resources allocated to prevention and appraisal activities. A continuation of this situation over the long term would lead to the business becoming uncompetitive as customers changed to competitor's products and high operating costs led to reduced margins. These findings confirm the difficulty that SMEs experience in allocating resources to strategic improvement programmes. Even though a structured approach was in place using a KTP programme, with a dedicated resource leading the change management process, the business imperative to cut costs to ensure survival derailed the implementation of Six Sigma.

\section{Conclusion}

For successful introduction of Six Sigma in Company B the cash flow of the business needs to be such that an increase in costs due to prevention and appraisal activities can be sustained over a long enough period to allow a systematic approach to Continuous Improvement to become established. 


\section{References}

1. Tannock, J., Balogun, O., Hawisa, H.: A variation management system supporting six sigma. Journal of Manufacturing Technology Management 18(5), 561-575 (2007)

2. Hutchins, D.: The power of Six Sigma in practice. Measuring Business Excellence 4(2), 26-33 (2000)

3. Bendell, T.: A review and comparison of six sigma and the lean organisations. The TQM Magazine, 255-262 (2006)

4. Antony, J.: Is six sigma a management fad or fact. Assembly Automation 27(1), 17-19 (2007)

5. Raisinghani, M.S.: Six Sigma: concepts, tools and applications. Industrial Management \& Data Systems 105(4), 491-505 (2005)

6. Choppin, J.: Recession or Opportunity. The TQM Magazine, 139-140 (1991)

7. Morgan, J.: The Lean Six Sigma Improvement Journey. Catalyst Consulting Limited (2006)

8. Dick, B.: Postgraduate programs using action research. The Learning Organization 9(4), 159-170 (2002)

9. Nonthaleerak, P., Hendry, L.: Exploring the six sigma phenomenon using multiple case study evidence. International Journal of Operations \& Production Management 28(3), 279 303 (2008)

10. Prestwood, D., Schumann, P.: Discovering Opportunities and Threats in a Market. The Innovation Road Map (2002) 